\title{
Analysis of Exponent K Based on "Share" Project Data and Its Implications on Importance Factors of En 1998-1
}

Dejan Dragojevic ( $\sim$ dragojevic.dejan@yahoo.com )

IZIIS https://orcid.org/0000-0002-6551-4200

Radmila Salic

IZIIS

Zoran Milutinovic

IZIIS

\section{Research Article}

Keywords: seismic hazard, return period, exponent k, importance factor, EN 1998-1

Posted Date: July 28th, 2021

DOI: https://doi.org/10.21203/rs.3.rs-746902/v1

License: (c) (i) This work is licensed under a Creative Commons Attribution 4.0 International License.

Read Full License

Version of Record: A version of this preprint was published at Bulletin of Earthquake Engineering on February 8th, 2022. See the published version at https://doi.org/10.1007/s10518-022-01333-y. 


\section{Abstract}

This paper deals with seismic activity represented by a hazard curve through a single parameter exponent $k$ as given in EN 1998-1, as well as with its implications on importance factors. We have used the SHARE project dataset for calculation of exponent $k$ for the wider European area and limited number of separate national studies for comparison of results since comparison to the SHARE results on the same dataset resulted with values of exponent $\mathrm{k}$ smaller by $1-1.5$. The results indicate that recommended value of exponent $\mathrm{k}$ of 3 is rather an exception than expected value in seismically active regions, and that with the exclusion of Vrancea zone, for majority of Europe exponent $k$ is well below assumed in EN 1998-1, which consequently indicate that importance factors for these locations should be larger than recommended in EN 1998-1.

\section{Introduction}

Exponent $k$ is defined in the note of article 2.1(4) of EN 1998-1 [1] by means of annual rate of exceedance. As stated in this article, it is assumed that annual rate of exceedance $\mathrm{H}\left(\mathrm{a}_{\mathrm{gR}}\right)$ may be taken to vary with $\mathrm{a}_{\mathrm{gR}}$ as:

$H\left(a_{g R}\right) \sim k_{0} a_{g R}^{-k}$

where $\mathrm{a}_{\mathrm{gR}}$ is reference peak ground acceleration on ground type $\mathrm{A}$, and $\mathrm{k}$ exponent that correlates reference peak ground acceleration with annual rate of exceedance. It is also stated in the article that exponent $\mathrm{k}$ is dependent on seismicity, but that is generally of the order of 3 .

With the given rather simplified link between hazard curve and exponent $k$ defined in equation (1), hazard curve is practically approximated by an exponent function, which is equivalent to a linear function on a log-log scale. The note does not provide further instructions how to determine exponent $k$, neither on what range, but it is reasonable to assume that in particular case interest is on return periods which are of concern for design of structures, and which are predefined in EN 1998-1 by choice of importance factors, which will be discussed in more detail further in the text.

In addition, because of the characteristics of probabilistic modelling of seismic hazard that is ultimately represented in the shape of annual rate of exceedance curve, it is impossible to define single $k$ value that can be representative to the whole possible range of the curve. This implies that the $k$ value is valid only within the limited determined range, the narrower the range, the more accurate the approximation is.

Importance factor $\gamma_{1}$, introduced in EN 1998-1, express peak ground acceleration of arbitrary return period $T_{L}$ related to the reference return period $T_{L R}$ as:

$$
\gamma_{I} \sim\left(\frac{T_{L R}}{T_{L}}\right)^{-\frac{1}{k}}
$$

and is also related to exponent $\mathrm{k}$ through different return periods. The idea behind this concept is to use single seismic hazard map for design, corresponding to the reference return period (recommended as 475 
years), while different return periods can be taken into account with importance factors calculated according to equation (2). Although this concept simplifies design procedure, it contains drawbacks which are inherent in the approximation process.

\section{Importance Factors And Exponent K}

In EN 1998-1 buildings are categorized into four different importance classes - from I to IV, where importance class I corresponds to buildings of minor importance to public safety, and importance class IV to buildings of vital importance for civil protection. Importance factors are ascribed to each importance class (article 4.2.5 of EN 1998-1) with recommended values of 0.8, 1.0, 1.2 and 1.4 for importance classes I to IV, subjected to changes in national annexes. Importance class II is related to ordinary buildings for which the importance factor of 1.0 is ascribed, which is related to reference peak ground acceleration (475 years).

Given the predefined value of exponent $k$ and recommended importance factors, it is possible to determine return periods corresponding to each importance factor using Eq. (2), which are presented in the first column of Table 1. For importance classes I to IV return periods are $243,475,821$ and 1303 years respectively. Return periods calculated in such way can be used to calculate importance factors for other values of exponent $k$, as presented in Table 1.

Table 1

Importance factors $\left(\mathrm{Y}_{1}\right)$ calculated for return periods that correspond to recommended values of importance factors and different values of exponent factor $k$

\begin{tabular}{|llllll|}
\hline$T_{\mathbf{L}}$ & $\mathbf{k}=\mathbf{1 . 5}$ & $\mathbf{k}=\mathbf{2 . 0}$ & $\mathbf{k}=\mathbf{2 . 5}$ & $\mathbf{k}=\mathbf{3 . 0}$ & $\mathbf{k}=\mathbf{4 . 0}$ \\
\hline 243 & 0.64 & 0.72 & 0.77 & 0.80 & 0.85 \\
475 & 1.00 & 1.00 & 1.00 & 1.00 & 1.00 \\
821 & 1.44 & 1.31 & 1.24 & 1.20 & 1.15 \\
1303 & 1.96 & 1.66 & 1.50 & 1.40 & 1.29 \\
\hline
\end{tabular}

Calculated results indicate that in less seismically active regions, which correspond to smaller values of exponent $k$, larger values of importance factors are required for importance classes III and IV in order to preserve same level of safety (expressed in return period) as in areas with assumed seismicity represented by exponent factor of 3. On the other hand, in higher seismicity areas lower values of importance factors can be used for same level of safety for importance classes III and IV.

The calculation is also presented in Fig. 1 where for various values of exponent $k$, the relationship between return period and importance factor is presented. The appearance of rotating effect of curves around the focal point of importance factor equal to 1, suggest that less seismically active areas require more time to express their full earthquake potential compared to areas with higher seismic activity. For 
instance, in low seismicity areas represented by exponent $k$ of 1.5 , importance factor of $\gamma_{1}=1.4$ would correspond to peak ground acceleration for return period of 787 years, instead of 1303 years. Therefore, keeping the recommended importance factor in less seismically active areas represented by an exponent factor lower than 3 would lead to underestimation of design forces for structures of importance classes III and IV, i.e. it would be as if we have used acceleration values from seismic hazard map for return period of 787 years, instead of 1303 years. Inverse effect is presented for importance factor of $\gamma_{1}=0.8$, however the difference is not as prominent, and this importance factor is related to structures of minor importance for public safety.

\section{Calculation Of Exponent Factor K From Efehr Data}

Data for calculation are downloaded from EFEHR website (www.efehr.org) using provided MATLAB routine. Requested data correspond to rock conditions $\left(\mathrm{v}_{\mathrm{s}, 30}>800 \mathrm{~m} / \mathrm{s}\right)$, arithmetic mean aggregation level, and for peak ground acceleration, which is consistent with EN 1998-1 requirements for hazard maps. A note should be given that hazard values on EFEHR website are calculated for probability of exceedance in 50 years - not for annual rate of exceedance. This can be verified using online request for hazard curve for arbitrary calculation point, calculating PGA value for return period of 475 years, and comparing the result to provided value at website. Therefore, in order to determine exponent $\mathrm{k}$ according to EN 1998-1 requirements, it is first necessary to transform data from probability of exceedance in 50 years into annual rate of exceedance.

Another question arises in the process of approximation - the choice of approximation range. As stated before, due to the specific shape of the hazard curve it is not possible to accurately approximate the hazard curve using Eq. 1 on the entire range of calculated values. This leads to conclusion that the fewer points are included into the approximation, the more accurate approximation is. Approximation range and narrowing the number of approximation points must be justified with the design application of approximated range which can be roughly estimated from calculated return periods presented in Table 1 (if recommended reference return period of 475 years is used). Also, recommendation from SHARE Deliverable 2.7 [2] was considered in which periods between 70 and 5000 years are used. Similarly, to that proposition, in this study starting year was used to be not less than 70 years and end year to be not greater than 5000 years, as years very between calculation points. As can be seen from histogram and distribution map on Fig. 2, for the vast majority of calculation points start year correspond to range between 70-120 years, although start year can be as high as 1000 years. Such case is for small number of points concentrated in areas of very low seismic hazard where even the lowest values of acceleration used in calculation require high return periods. These points are concentrated on the south eastern border of Finland and Russia, eastern part of Ukraine, and western Ireland. Nonetheless for the vast majority of calculation points start year is well below 243 years, which correspond to importance factor of 0.8 , or likewise well below 475 year, i.e., the start year can be considered relevant for approximation regarding purpose of exponent $\mathrm{k}$. 
End year for approximation range was defined as data that correspond to the first year from calculation dataset that is lower or equal to 5000 years. As calculation points tend to be coarser with increasing acceleration values for areas of high hazard the end year tend to be smaller than in areas with lower seismic hazard. Geographical distribution map and histogram are presented in Fig. 3 where it can be noticed that distribution of end years is more evenly distributed. Considering validity of minimum used end year regarding maximum year covered by importance factor, it can be concluded that all points are greater than 1303 years which correspond to recurrence period bonded to importance factor of $\gamma_{1}=1.4$ (importance class IV), i.e. the selection is relevant for approximation.

One more relevant issue that should be mentioned in the approximation process is the number of points included in approximation for each calculated hazard point which is presented in Fig. 4. Number of used points in approximation is to some degree related to inherent error of approximation process, however the overall accuracy also depends on the range between start year and end year. As can be seen in geographic distribution map, the more seismically active area is - the less points are used in approximation. This is inevitably the result of chosen points of acceleration in calculation of seismic hazard which are given as results at EFEHR website and cannot be changed, and chosen boundaries for start and end year of approximation. Total number of points varies between 3 and 14 . Seismically active areas include less points and oppositely less seismically active areas include more points.

Final step is linear approximation of hazard curve on a log-log scale on a given range, which is equivalent to exponential function of approximation given in Eq. 1.

\section{Results}

Calculated results of exponent $k$ for arithmetic mean values of PGA on ground type $A$ are presented on Fig. 5. Unlike stated in the article 2.1(4) of EN 1998-1 that for most sites exponent $k$ is generally of the order of 3 , the results indicate that value of exponent factor $k$ of 3 is rather an exception than expected value. Value of exponent factor of the order near 3 , but still lower than 3 , is expected only in wider Vrancea region originating from Vrancea intermediate seismic zone. For seismically active parts of Mediterranean and Iceland, exponent $k$ is of the order of 2.5, north and northwestern Balkan Peninsula of the order of 2, on Iberian Peninsula values vary between 1.2 and 2.2. There is general trend of decreasing values of exponent $k$ in continental part of Europe with increasing latitude. Western Scandinavia has values of exponent $k$ exceeding 1.5 , and for some points even reach value of 2 , while on eastern Scandinavia values fall below 1 . The lowest calculated $k$ values being of the order of 0.5 are located in the southeastern border zone between Russia and Finland.

Another comparison could be made with map of exponent k given on Fig. 3.13a in Deliverable 2.7 of the SHARE project where obtained results show around 1-1.5 higher values of exponent $k$ than in this study. The difference is due to incorrect determination of exponent $k$ in SHARE study on hazard curve given for probability of exceedance in 50 years, instead on annual rate of exceedance hazard curve. This is clearly noticeable on Fig. 3.12 of the mentioned deliverable with presented hazard curves for chosen cities. 
Namely, the $y$ axis is labeled as "annual rate of exceedance", however by obtaining results from the EFEHR website it is easily noticeable that given results in fact represent values of probability of exceedance in 50 years. Hence the calculation of exponent $k$ in SHARE deliverable was determined on the unrepresentative part of the hazard curve, leading to false conclusion that recommended value of exponent k in EN 1998-1 is valid for most part of seismically active areas of Europe.

Values of exponent $\mathrm{k}$ can be perceived in more detail in Table 2 for chosen sites across Europe. Sites are chosen to correspond to the one defined in SHARE Deliverable 2.7. Again, most of the values of exponent $k$ in SHARE study are stacked around value of 3 , while results of this study indicate for much lower values.

Table 2

Values of exponent $\mathrm{k}$ for chosen sites

\begin{tabular}{|lllll|}
\hline City & Lon & Lat & \multicolumn{2}{c|}{ exponent k } \\
\cline { 4 - 5 } & & & this study & SHARE \\
\hline Basel & 7.5821 & 47.6000 & 1.8227 & 3.3192 \\
\hline Bergen & 5.3821 & 60.4000 & 1.5661 & 2.7040 \\
\hline Bucharest & 26.1820 & 44.5000 & 2.4157 & 4.2177 \\
\hline Istanbul & 29.8821 & 41.0000 & 2.1824 & 2.7983 \\
\hline Cologne & 6.9821 & 50.9000 & 1.6417 & 2.7810 \\
\hline L'Aquila & 13.3821 & 42.3000 & 2.2207 & 3.3730 \\
\hline Lisbon & -9.1179 & 38.7000 & 1.7865 & 3.1420 \\
\hline Palermo & 13.3821 & 38.1000 & 2.1608 & 3.4605 \\
\hline Rhodes & 28.1821 & 36.4000 & 2.1839 & 2.3956 \\
\hline Thessaloniki & 22.8821 & 40.6000 & 2.1670 & 3.2116 \\
\hline Wien & 16.3821 & 48.2000 & 1.7385 & 2.8884 \\
\hline NW Norway & 5.0300 & 60.8100 & 1.6427 & 2.6066 \\
\hline
\end{tabular}

Hazard curves for chosen sites are presented in Fig. 6 both with determination range for exponent $\mathrm{k}$ used in this study and SHARE project. Instead of stated range [2] between 70 and 5000 years, the SHARE study actually determined exponent $k$ on a range between 3475 and 249975 years where the values of peak ground acceleration take values around $1 \mathrm{~g}$.

\section{Values Of Exponent K In National Studies}


To some extent values of exponent $\mathrm{k}$ are available from various national studies of seismic hazard that give good source for cross validation of results.

Considering the most active seismic zone in Europe (based on results of SHARE study [2]) - the Vrancea intermediate depth seismic zone, national studies of exponent $k$ known to authors are available for Romania and Bulgaria.

Seismic hazard analysis for Romania [3] deals in some detail with this topic as it gives separate figures for exponent $\mathrm{k}$ for national study and SHARE study. For the national study the determination range of exponent $\mathrm{k}$ was between 30 and 2475 years, which is somewhat different than in SHARE study, but not in a way that could compromise comparison of results. This paper showed that in SHARE study Vrancea source zone total territory coverage with maximum exponent $\mathrm{k}$ is much smaller compared to the national study.

Seismic hazard study of Bulgaria [4] showed values of exponent $k$ ranging from 1.6 to 4.8 , the latter being controlled by the Vrancea intermediate seismic hazard zone. The maximum values of exponent $k$ obtained in national study are much higher than the ones in SHARE study [2] where this part of northern Bulgaria has values of exponent $k$ of approximately 2.2. The high values of exponent $k$ in national study also cover significant part of northern border zone with Romania.

For Italy, seismically active country that should be representative for recommended value of exponent $k$ given in EN 1998-1, interactive results of seismic hazard are available online via INGV service [5], which can be used for determination of exponent $\mathrm{k}$. For $50 \%$ percentile, and available range of data that correspond to return periods between 30 and 2500 years, the values of exponent $k$ in areas of highest hazard are of the order of 2.5 which is similar to results in this study. Considering Table 1 , the difference of importance factors for categories III and IV is $3 \%$ and $7 \%$.

It is interesting to compare studies in areas with lower seismic hazard to the results of this study. For countries where no separate published studies on exponent $k$ were found, we used values of importance factors in National Annexes for comparison. For instance, in Norwegian National Annex for EN 1998-1 [6] values of importance factors of $0.7,1.0,1.4$ and 2.0 correspond to value of exponent $k$ approximately 1.5 , which is in good correlation with results of this study based on SHARE data (Table 2). Sweden has not yet issued national annex for EN 1998-1, but in study [7] exponent $k$ is calculated for the city of Lund where value of 1.4 is obtained, which is similar to results in this study (Fig. 5). On the other hand, Germany [8] - left recommended values of importance factors in their National Annex although the seismic activity should lead to much higher importance factors. For example, the values of importance factors for the city of Cologne (Table 2) are thus underestimated by $16 \%$ and $32 \%$ for importance classes III and IV. Likewise, National Annex for France [9] leaves to the municipal authorities to determine values of importance factors, not mentioning that the values of exponent $k$ dictate values of importance factors - i.e., that it is not purely political decision. From [10] it seems that single categorization is used for the entire country of France. United Kingdom [11] used base map for 2500 years and importance factor of 
1.0 , but in cases where $T_{N C R}$ is determined on a project - specific basis, the importance factor should be determined as well.

\section{Discussion}

Final goal of calculation of exponent $\mathrm{k}$ based on a seismic hazard study should be determination of importance factors (Eq. 2). To preserve the same level of safety as recommended value of exponent $\mathrm{k}$ given in EN 1998-1, importance factors should be proportionally scaled (Eq. 2) to match the difference in local seismic activity to recommended one. Based on the results in this study, as well on national studies [3-6] the conclusion arises that considering territory of a country, rarely can single value of exponent $k$ be ascribed to the whole national territory with fair accuracy. It is more likely that at best several values must be ascribed to different parts of national territory which can be accomplished by applying different values of exponent $\mathrm{k}$ (importance factors) to different seismic zones. However, to our best knowledge this was not applied in any of the National Annexes of EN 1998-1 yet. The most accurate solution would be of course to ascribe different $k$ value to each seismic hazard calculation point, but strictly speaking this is not possible according to EN 1998-1.

Results of exponent $k$ determined in this study are much lower than the results of the SHARE study [2] on the same data by due to the fact that in the SHARE study exponent $k$ is mistakenly determined on a nonrepresentative part of the hazard curve. For most locations difference is of the order of 1-1.5. Therefore, for the majority of locations in Europe exponent $k$ is well below recommended value [1] of exponent $k$ of 3.0 which further indicate that this value is probably too high to be as recommended one for most part of Europe's active seismic zones with the exception of Vrancea intermediate depth seismic zone. Considering results of this study it is more likely that exponent $k$ of the order of 2 is more representative for seismic activity of the European continent. The consequence of stated is that assuming the recommended value of exponent k, i.e., accepting the recommended values of importance factors would lead to underestimation of seismic hazard for importance classes III and IV for as much as $40 \%$ for importance class IV.

\section{Declarations}

Funding - No funds, grants, or other support was received

Conflicts of interest/Competing interests - The authors have no conflicts of interest to declare that are relevant to the content of this article.

Availability of data and material (data transparency) - not applicable

Code availability - not applicable

Authors' contributions - All authors who deserve authorship are listed 
Ethics approval - not applicable

Consent to participate - All authors freely chosen to participate in study

Consent for publication - All authors freely chosen to publish this material

\section{References}

1. EN 1998-1:2004, Eurocode 8: Design of structures for earthquake resistance - Part 1: General rules, seismic actions and rules for buildings, CEN/ European committee for standardization

2. Deliverable 2.7 - Preliminary Reference Euro-Mediterranean Seismic Hazard Zonation[i]

3. Pavel, F., Vacareanu, R., Douglas, J. et al. Pure Appl. Geophys. (2016) 173: 1881. https://doi.org/10.1007/s00024-015-1223-6

4. Сеизмично райониране на Република България, съобразено с изискванията на Еврокод 8 “Сеизмично осигуряване на строителни конструкции" и изработване на карти за сеизмичното райониране с отчитане на сеизмичния хазарт върху територията на страната, Българска Академия на Науките, Геофизичен Институт “Акад. Л. Кръстанов” ,Отчет ГФИ 07-03, София, Ноември 2009 г. (in Bulgarian).

Seismic zoning of the Republic of Bulgaria, in accordance with the requirements of Eurocode 8 "Seismic provision of building structures" and production of maps for seismic zoning taking into account the seismic hazard on the territory of the country, Bulgarian Academy of Sciences, Geophysical Institute "Acad. L. Krustanov", GFI 07-03, Sofia, November 2009.

5. http://esse1-gis.mi.ingv.it/s1_en.php

6. NS-EN 1998-1:2004+A1:2013+NA:2014, Norwegian National Annex for EN 1998-1

7. Erik Larsson and Lucas Magnusson, Evaluation of seismic action in Sweden using the European seismic hazard model, Master's Dissertation, Faculty of Engineering LTH, Lund University, Sweden, 2017

8. DIN EN 1998-1/NA, German National Annex for EN 1998-1

9. NF EN 1998-1/NA, French National Annex for EN 1998-1, 2007

10. La nouvelle Réglementation Parasismique applicable aux bâtimentsdont le permis de construire est déposé à partir du $1^{\text {er }}$ mai 2011, Janvier 2011, Ministère de l'Écologie, du Développement durable, des Transports et du Logemenent

11. BS NA EN 1998-1, National Annex for United Kingdom

\section{Figures}




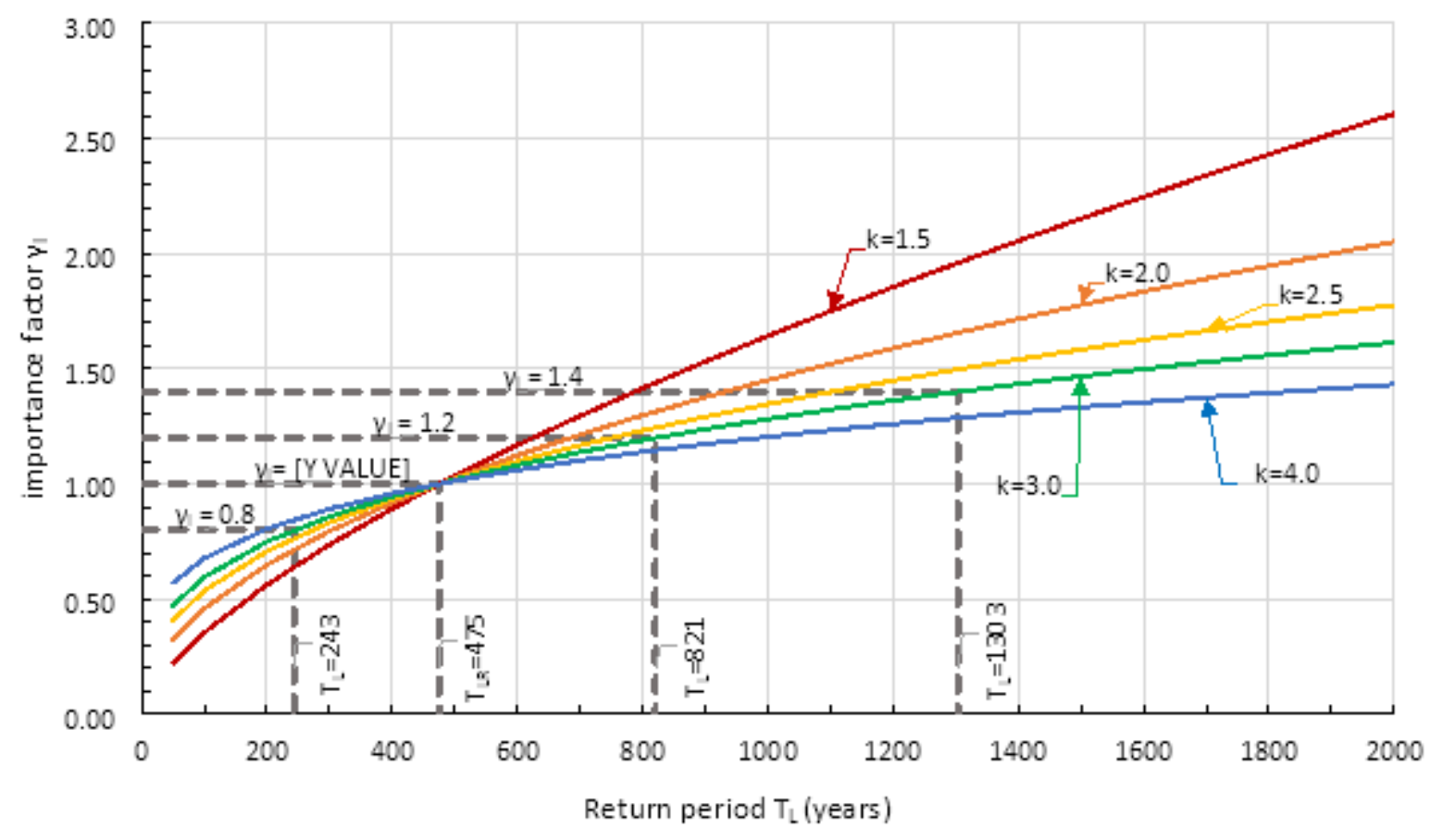

Figure 1

Relationship between return periods and importance factors for different values of exponent factor $k$

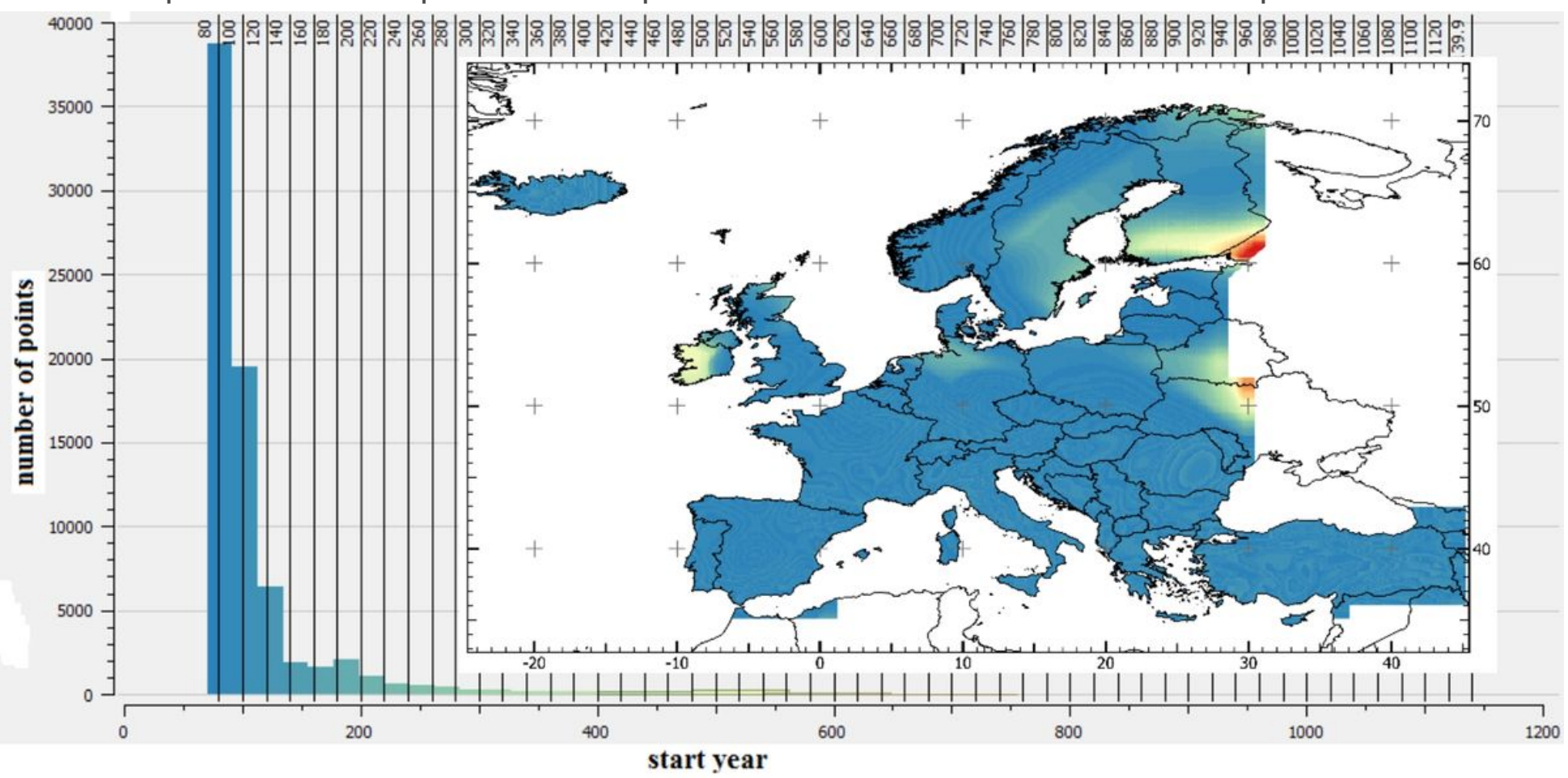

Figure 2

Histogram of number of points per bin for start year used for the approximation of hazard curve with distribution map 


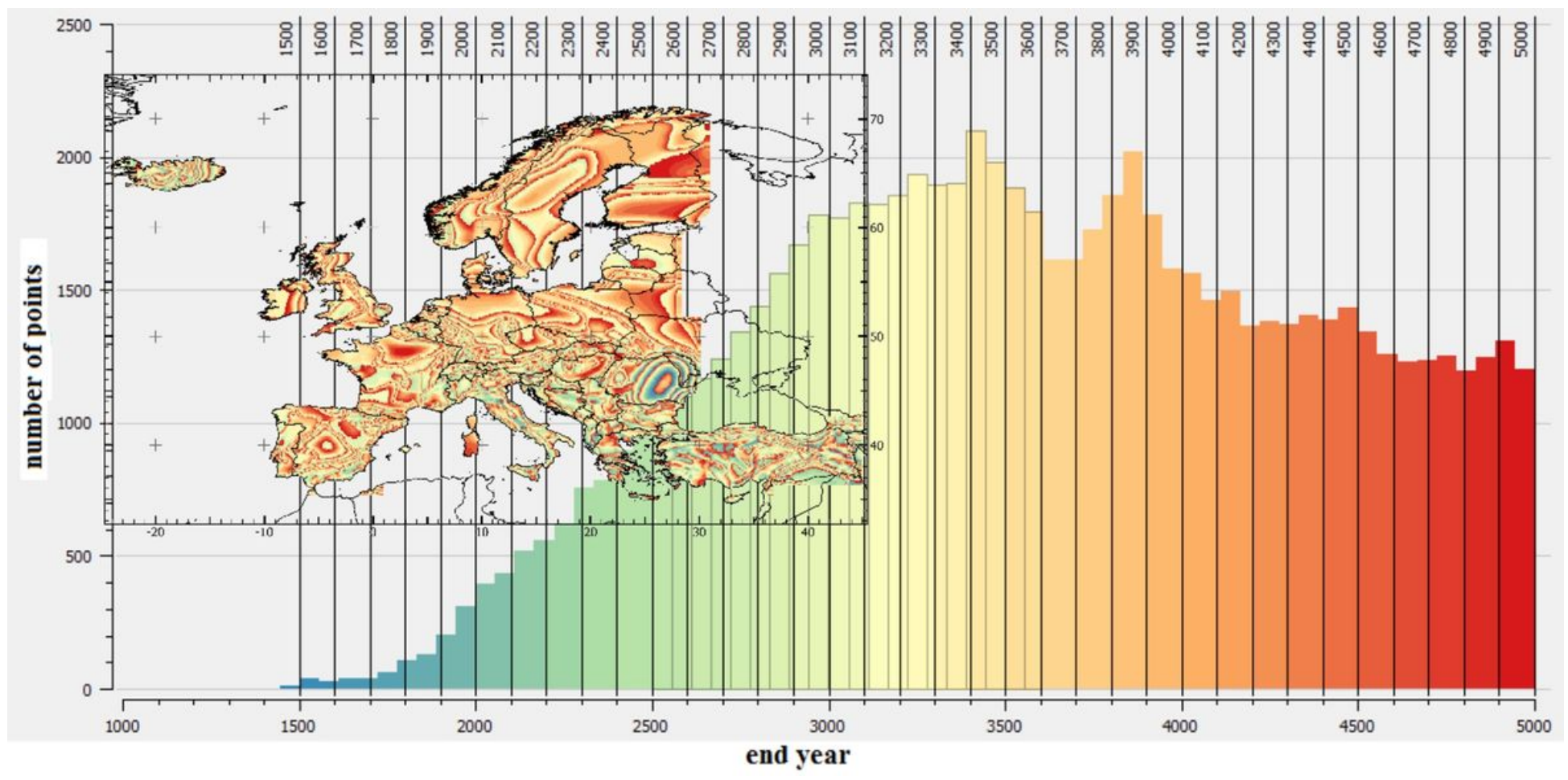

Figure 3

Histogram of number of points per bin for end year used for the approximation of hazard curve with distribution map

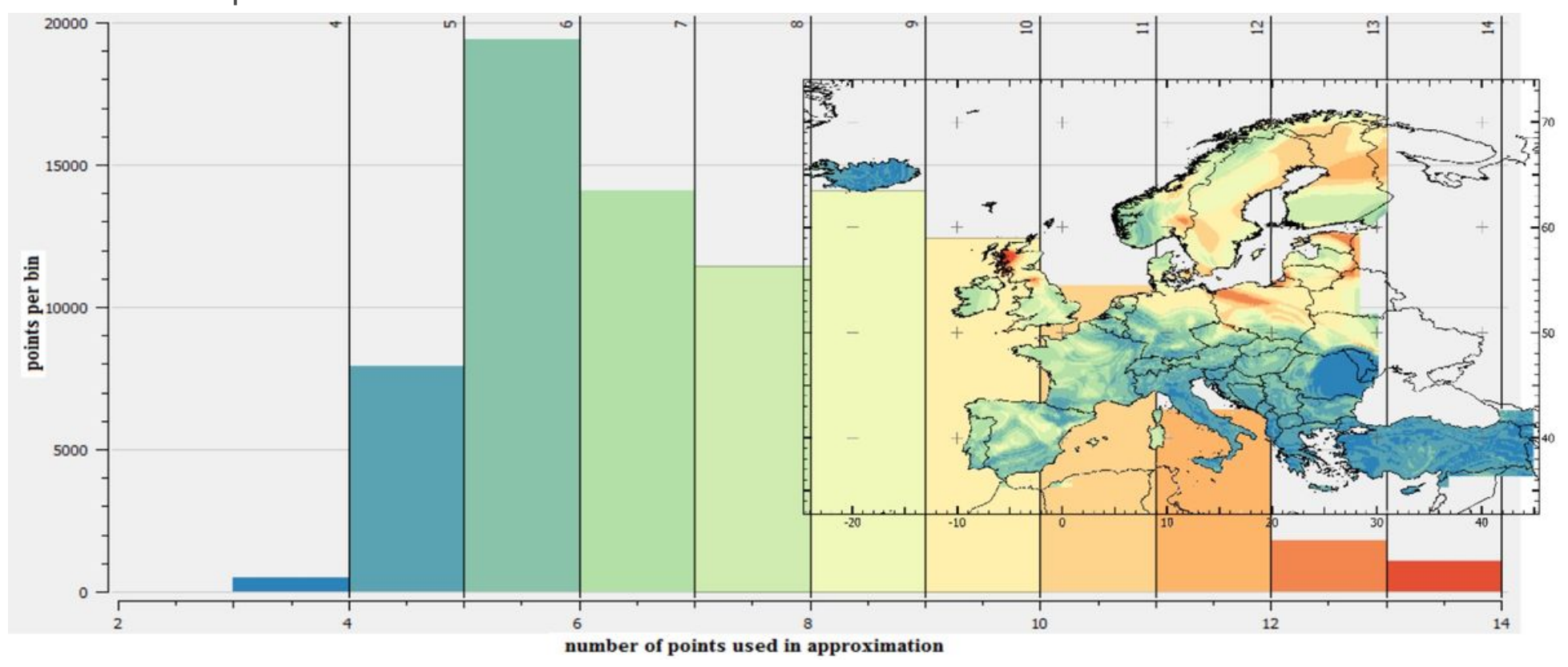

Figure 4

Number of points used in approximation - histogram and geographic distribution map 


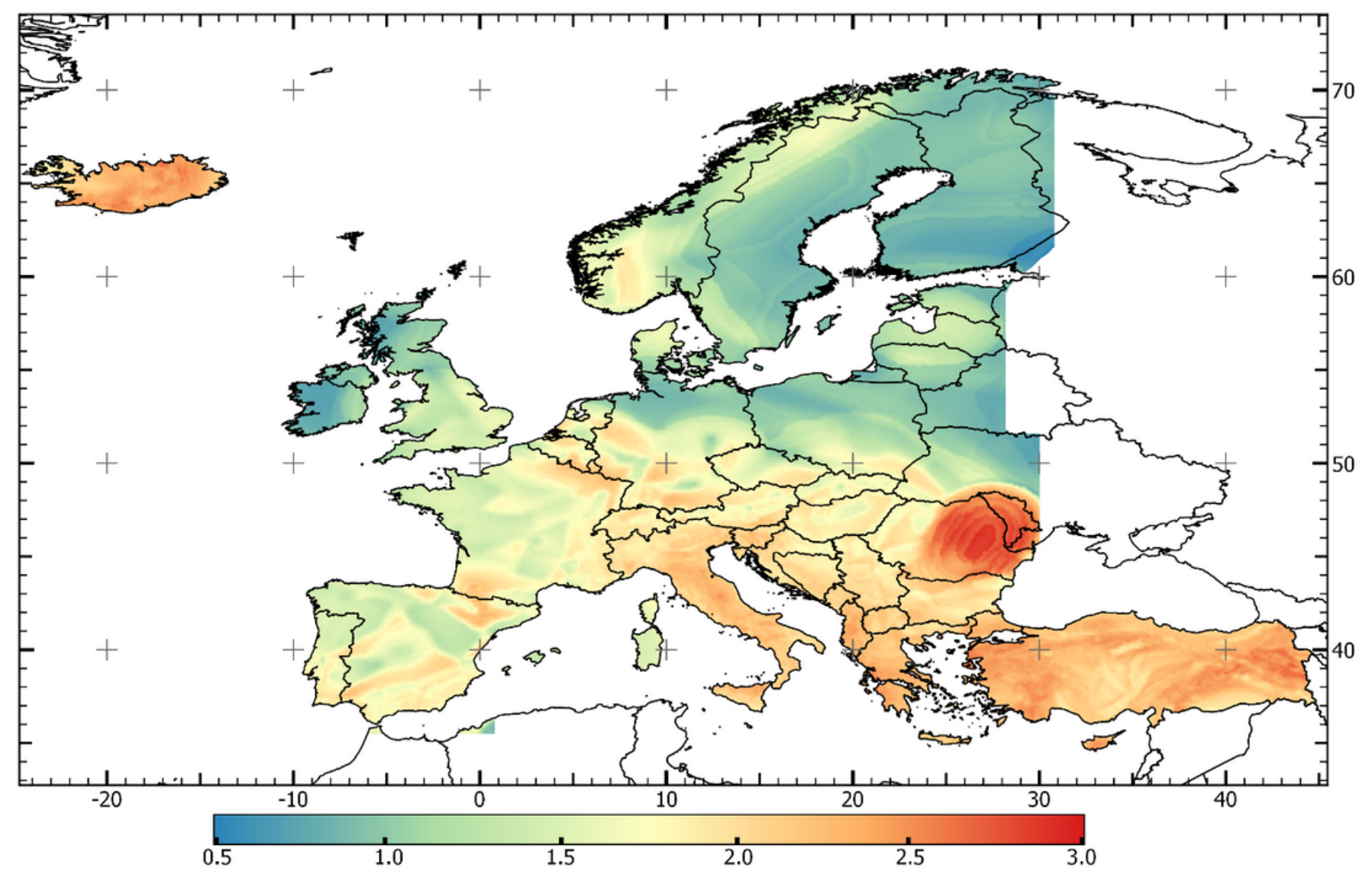

Figure 5

Distribution map of Exponent $\mathrm{k}$ - arithmetic mean values for PGA hazard and soil type A 

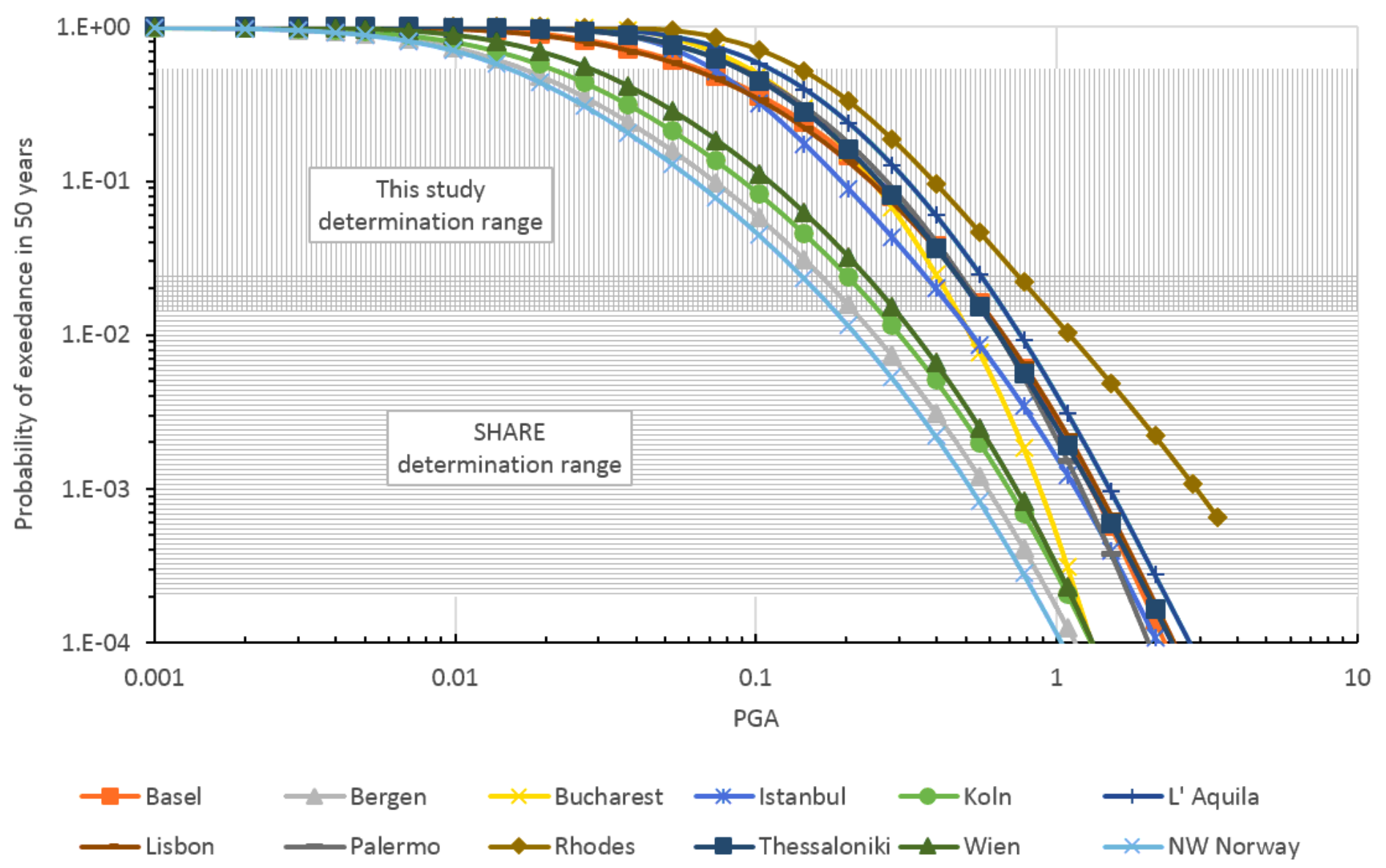

Figure 6

Hazard curves for chosen sites across Europe with shaded determination ranges for exponent $k$ in SHARE study, and in this study 